\title{
Reduced High-Latitude Land Seasonality in Climates with Very High Carbon Dioxide
}

\author{
MATTHEw HenRYa AND GeOFFRey K. VALLis ${ }^{\mathrm{a}}$ \\ ${ }^{a}$ Department of Mathematics, University of Exeter, Exeter, United Kingdom
}

(Manuscript received 12 February 2021, in final form 9 June 2021)

\begin{abstract}
Observations of warm past climates and projections of future climate change show that the Arctic warms more than the global mean, particularly during winter months. Previous work has attributed this reduced Arctic land seasonality to the effects of sea ice or clouds. In this paper, we show that the reduced Arctic land seasonality is a robust consequence of the relatively small surface heat capacity of land and the nonlinearity of the temperature dependence of surface longwave emission, without recourse to other processes or feedbacks. We use a general circulation model (GCM) with no clouds or sea ice and a simple representation of land. In the annual mean, the equator-to-pole surface temperature gradient falls with increasing $\mathrm{CO}_{2}$, but this is only a near-surface phenomenon and is not caused by the change in total meridional heat transport, which is virtually unaltered. The high-latitude land has about twice as much warming in winter than in summer, whereas high-latitude ocean has very little seasonality in warming. A surface energy balance model shows how the combination of the smaller surface heat capacity of land and the nonlinearity of the temperature dependence of surface longwave emission gives rise to the reduced seasonality of the land surface. The increase in evaporation over land also leads to winter amplification of warming over land, although amplification still occurs without it. While changes in clouds, sea ice, and ocean heat transport undoubtedly play a role in high-latitude warming, these results show that enhanced land surface temperature warming in winter can happen in their absence for robust reasons.
\end{abstract}

SIGNIFICANCE STATEMENT: As we add greenhouse gases to the atmosphere, Earth's surface gets warmer, and this is especially pronounced in the Arctic in winter. For the current and near-future climate, this is at least in part due to the melting of sea ice. However, as time progresses all the sea ice melts, and even after that climate models show enhanced polar warming, with most of the warming occurring over Arctic land in winter. Moreover, fossils indicate that the very warm climates of the past (some 50 million years ago for example) had exceptionally warm Arctic winters. Previous work has attributed this reduced seasonality over Arctic land to the effects of sea ice or clouds. Here, we identify a robust mechanism, based on the smaller heat capacity of land and the fact that cold bodies need to warm more to reach a given increase in radiation, as to why Arctic land should have a reduced seasonality in very warm climates. The mechanism depends on neither sea ice nor clouds.

KEYWORDS: Arctic; Climate change; Paleoclimate; Idealized models

\section{Introduction}

The early Eocene (48-56 million years ago) had an "equable climate" with a smaller equator-to-pole temperature gradient than today, at least at the surface, with year-round abovefreezing temperatures at high-latitude continents. Proxy records indicate that at latitudes around $75^{\circ} \mathrm{N}$, the annual-mean temperature was about $8^{\circ} \mathrm{C}$, the cold month mean temperature was between $0^{\circ}$ and $3.5^{\circ} \mathrm{C}$, and the warm month mean temperature was between $19^{\circ}$ and $20^{\circ} \mathrm{C}$ (Eberle et al. 2010; Evans et al. 2018). Carbon dioxide concentrations in the early Eocene are uncertain, and have been variously estimated to be as little as 600 ppm or well over 4000 ppm (Beerling and Royer 2011).

Understanding the temperature structure under such conditions is sometimes called the "equable climate problem" since although very warm high latitudes can be achieved simply with very high values of $\mathrm{CO}_{2}$ or other greenhouse gases, simulations often give rise to very high tropical temperatures, possibly incompatible with proxy records (Huber and Caballero 2011). However, the incompatibility is itself uncertain as more recent proxies of early Eocene tropical SSTs

Corresponding author: Matthew Henry, m.henry@exeter.ac.uk do indicate temperatures warmer than previously estimated, and tropical temperature estimates tend to have large error margins (Pearson et al. 2007). Nevertheless, the balance of evidence is that in equable climates, the increase in temperature at high latitudes (compared to the temperature of today) was greater than the increase at low latitudes, at least in winter months. This result is not fully understood, for it implies either a greater meridional heat transport in the atmosphere-ocean system or a change in the vertical temperature structure of the atmosphere, or some change in seasonality, or a combination of these effects. Maintaining above-freezing temperatures over land in highlatitude winter seems particularly problematic, since the low heat capacity of land suggests that temperatures will cool rapidly in winter when there is no incoming solar radiation.

As in past warm climates, the surface temperature change at high latitudes is amplified in projections of future climate change (Holland and Bitz 2003). This has been variously attributed to the surface albedo feedback [critically discussed by Winton (2006)], a temperature feedback (Pithan and Mauritsen 2014), and increased meridional atmospheric energy transport (Hwang and Frierson 2010). While the surface albedo feedback increases high-latitude surface warming, it also leads to a decrease in the dry component of atmospheric 
energy transport convergence (Hwang et al. 2011; Henry et al. 2021). Investigation of the vertical structure of temperature change also shows that, at high latitudes, the $\mathrm{CO}_{2}$ forcing and water vapor feedback lead to surface-enhanced warming (Taylor et al. 2013; Henry et al. 2021), in contrast to the tropics where convection fixes the vertical structure of temperature to the moist adiabat.

The amplified Arctic winter warming under anthropogenic global warming has been attributed to increased seasonal heat storage in the ocean in summer and ocean heat release in winter as Arctic sea ice is reduced, which, in combination with a surface-enhanced vertical structure of atmospheric temperature change, potentially leads to more warming in winter (Bintanja and van der Linden 2013; Pithan and Mauritsen 2014). Dwyer et al. (2012) analyze changes in the seasonal cycle of surface temperature over the whole planet and find a key role for the increase in heat capacity induced by sea ice melt to explain the reduction in seasonality over the Arctic Ocean. A rather different explanation is given by $\mathrm{Lu}$ and Cai (2009), who analyze the surface energy budget of comprehensive climate models. They find that the increased winter warming is due to the clearsky longwave feedback, including the effects of a lapse rate change. Evidently, the roles of sea ice, seasonal heat storage, and the lapse rate change on the seasonality of polar amplification remain unclear, in part due to the difficulties of analyzing comprehensive climate models.

A number of simulations with comprehensive general circulation models (GCMs) have addressed these issues, both for past climates and future warming. Thus, for example, Huber and Caballero (2011) show that, by increasing $\mathrm{CO}_{2}$ to high but feasible concentrations in a fully coupled GCM, sufficient winter polar amplification occurs over land to maintain abovefreezing temperatures. The possible range of appropriate levels of $\mathrm{CO}_{2}$ concentration to best represent the early Eocene is still rather wide, though-they suggest between 2500 and $6500 \mathrm{ppm}$. Other models have given different results and the mechanisms responsible for enhanced winter warming are still debated. For example, Abbot and Tziperman (2008) show that deep convection and consequent cloud longwave radiative forcing can maintain warm Arctic temperatures over winter in high $\mathrm{CO}_{2}$ climates and Cronin and Tziperman (2015) discuss the role of low clouds in the formation of Arctic continental air masses. In winter, maritime air masses are advected onto continents: if their initial state is warmer, they are more likely to form low clouds, which suppresses surface radiative cooling and amplifies the continental surface warming. They report a $2^{\circ} \mathrm{C}$ increase in continental surface temperatures for every degree of initial maritime near-surface air temperature increase. Furthermore, Lunt et al. (2012) compare comprehensive GCM simulations of the early Eocene and find that clear-sky longwave feedbacks, surface albedo feedbacks, and aerosol loading are responsible for differences among GCMs, rather than cloud feedbacks or boundary conditions.

Our goal in this paper is to isolate and thereby better understand the various mechanisms involved in high-latitude warming. Although different mechanisms have been proposed for the seasonality of high-latitude temperature changes in both past warm climates and projected future climates, the decrease in seasonality of high-latitude land temperatures is a robust feature of both periods. The detailed configurations differ considerably between past warm climates and future anthropogenic warming (e.g., the presence of sea ice and the differing continental configurations), hence we focus on robust effects that can apply in both situations. To this end, we use a GCM with no sea ice, clouds, or ocean circulation, but with land-ocean contrasts and a comprehensive radiation scheme (Vallis et al. 2018). We find that high-latitude land warms more in winter and less in summer compared to the high-latitude ocean, in response to an increase in $\mathrm{CO}_{2}$ concentration. Moreover, the high-latitude atmospheric temperature change is surface enhanced in winter and more vertically homogeneous in summer. These results depend only on the smaller heat capacity of land compared to ocean and the nonlinearity of the temperature dependence of surface infrared emission.

In section 2, we describe our idealized GCM simulations and also analyze the high-latitude surface temperature change of two comprehensive Earth system models under a high emissions scenario. In section 3 , we use a simple surface energy balance model to show that the enhanced Arctic continent winter warming arises through the combination of the smaller land surface heat capacity and the nonlinearity of the temperature dependence of surface longwave emission. This can also be understood by using a forced damped oscillator model. In section 4, we discuss the seasonality of high-latitude atmospheric temperature change, which is surface enhanced in winter as the atmosphere is near radiative-advective equilibrium, but more vertically homogeneous in summer as the Arctic land gets warm enough to trigger convection. In section 5, we conclude and discuss the implications and limitations of this study.

\section{Experiments with general circulation models}

We use the Isca climate modeling framework (Vallis et al. 2018) in a fairly spare configuration. Specifically, we have no clouds or sea ice, and a slab ocean boundary condition, with a simple representation of land following present-day continental outlines. We impose a seasonal cycle of insolation and use the comprehensive SOCRATES (Suite of Community Radiative Transfer codes based on Edwards and Slingo) radiation scheme for both solar and infrared radiation (Manners et al. 2017; Thomson and Vallis 2019), with a constant surface albedo equal to 0.3 everywhere. In the form used here SOCRATES maintains good accuracy with $\mathrm{CO}_{2}$ levels up to a factor of 16 more than today. Land differs from oceans only by the depth of its mixed layer and hence its surface heat capacity, which we set to $2 \mathrm{~m}$ equivalent water depth for continents and $20 \mathrm{~m}$ depth for oceans, and by the roughness constant, which is set to be 10 times higher over land than ocean. We use today's distribution of continents. (The continents in the Eocene were different from today's but not appreciably so and landmasses such as North America, Greenland, and Europe are still recognizable.) Simulations are run at spectral T42 resolution, which corresponds to approximately $2.8^{\circ}$ resolution at the equator. Convection is calculated using a simplified Betts-Miller convection scheme (Frierson 2007). Large-scale condensation is parameterized such that relative 

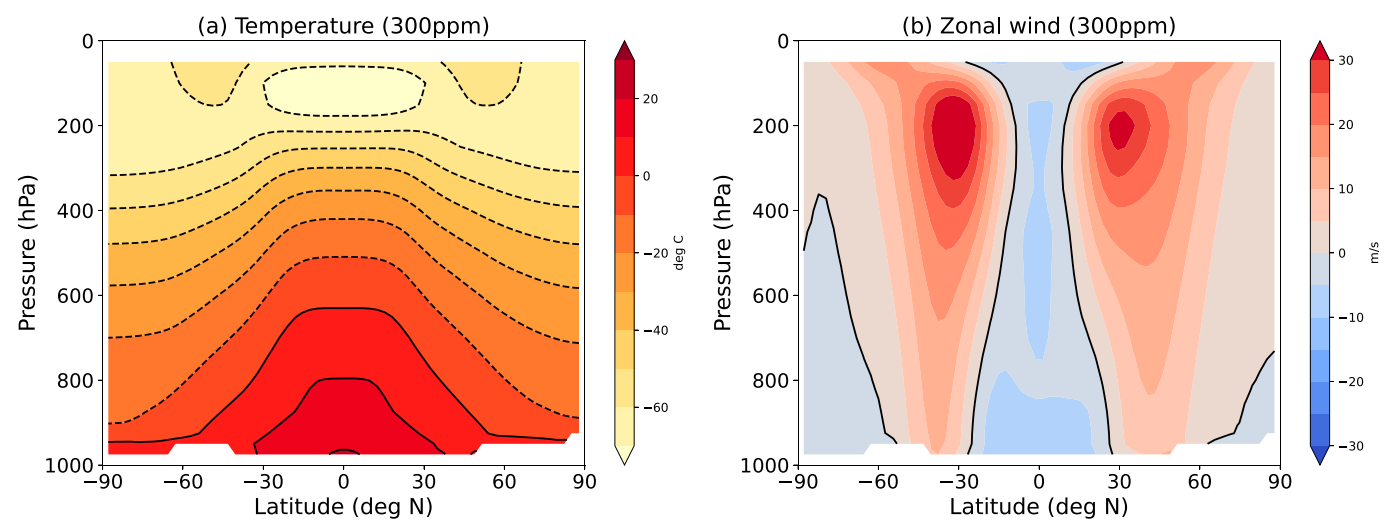

FIG. 1. (a) Zonal-mean temperature for the reference simulation $(300 \mathrm{ppm})$. (b) Zonal-mean zonal wind for the reference simulation $(300 \mathrm{ppm})$.

humidity does not exceed one, and condensed water immediately returns to the surface. This configuration thus (deliberately) excludes cloud feedbacks and effects of land surface changes, but maintains land-ocean contrasts and potential radiative-convective effects.

We first describe three simulations in which $\mathrm{CO}_{2}$ concentrations are set to $300,1200(4 \times 300 \mathrm{ppm})$, and $4800 \mathrm{ppm}$ $(4 \times 1200 \mathrm{ppm})$, respectively. Given the logarithmic nature of $\mathrm{CO}_{2}$ forcing with respect to concentration, the additional greenhouse effect from each quadrupling is similar, being just slightly higher for the second quadrupling than for the first (not shown). Later, we discuss all-land and all-ocean experiments, in which the depth of the mixed layer is set to $2 \mathrm{~m}$ and $20 \mathrm{~m}$, respectively, over the whole surface, and the roughness constant is set to that of ocean. Figure 1 shows the zonal-mean temperature and zonal wind profile of the reference simulation.

We derive the dry and moist components of the annualmean meridional atmospheric heat transport from the moist static energy flux as in Eq. (1) from Armour et al. (2019). The total atmospheric heat transport is remarkably constant across the three experiments, with the increase in moist atmospheric heat transport (arising from the higher temperature) being almost perfectly compensated by a decrease in dry atmospheric heat transport poleward of $30^{\circ} \mathrm{N}$ (Fig. 2). Consequently, the midtropospheric temperature gradient is about the same in all experiments. However, the surface meridional temperature gradient falls considerably with increased $\mathrm{CO}_{2}$ levels with increased high-latitude temperatures, enhanced over land in winter. The annual-mean surface temperature for land (solid) and ocean (dashed) for the control simulation (black) and increased $\mathrm{CO}_{2}$ simulations is shown in Fig. 3a. Figure 3b shows the surface temperature change as $\mathrm{CO}_{2}$ is increased from 300 to $1200 \mathrm{ppm}$ and from 1200 to $4800 \mathrm{ppm}$. Despite the absence of sea ice, the surface temperature change is polar amplified as the high-latitude atmosphere warms more near the surface in the absence of convection (Henry et al. 2021). The surface temperature change is about twice as large for the second quadrupling (1200-4800 ppm) than for the first (300$1200 \mathrm{ppm})$. This is mostly due to the much larger increase in absorbed solar energy for the second quadrupling as the atmosphere is warmer and moister (Fig. 4). The closing of the water vapor window may also make the clear-sky longwave feedback more destabilizing (McKim et al. 2021). In this set of simulations, the land and ocean warm by similar amounts in the tropics and midlatitudes, stemming from the fact that the evaporation is similar over the land and ocean and the air above land is as moist as the air above ocean. In a more realistic setup, the land evaporative resistance would be reduced, which makes the land warm more than the ocean (not shown).

Figure $3 \mathrm{c}$ shows the surface temperature averaged poleward of $70^{\circ} \mathrm{N}$ for land (solid) and ocean (dashed) for the control (black) and increased $\mathrm{CO}_{2}$ simulations $(1200 \mathrm{ppm}$ in blue and $4800 \mathrm{ppm}$ in red). The land temperatures stay above $0^{\circ} \mathrm{C}$ almost year-round in the $4800 \mathrm{ppm}$ simulation. Figure $3 \mathrm{~d}$ shows the difference between the 300 and $1200 \mathrm{ppm}$ simulations (blue) and the 1200 and $4800 \mathrm{ppm}$ simulations (red). There is a clear seasonality in land surface temperature change: for the difference between 300 and $1200 \mathrm{ppm}$, it reaches $13^{\circ} \mathrm{C}$ in winter and $6^{\circ} \mathrm{C}$ in summer, whereas ocean surface temperature change is around $8^{\circ} \mathrm{C}$ year-round.

Figure 5 shows the atmospheric temperature change between the 300 and $1200 \mathrm{ppm}$ simulations and between the 1200 and $4800 \mathrm{ppm}$ simulations for Northern Hemisphere (NH) winter and summer. For the first quadrupling (Figs. 5a,b), the $\mathrm{NH}$ high-latitude temperature change is surface enhanced in winter and top heavy in summer. For the second quadrupling, the NH high-latitude temperature change is top heavy year round, but more so in summer. The seasonality of atmospheric temperature change is investigated in section 4.

Comprehensive climate model simulations of a high anthropogenic emissions scenario also show enhanced warming over high-latitude land in winter. While amplified winter warming is expected with sea ice loss (Bintanja and van der Linden 2013), winter amplification of land warming also occurs when sea ice has melted. Figure 6 shows results from two comprehensive climate models: the Canadian Earth System Model version 5 (CanESM5) and the Institut Pierre Simon Laplace Coupled Model, version 6a, low resolution (IPSLCM6A-LR), under a high emissions scenario [the Shared 
(a) Total atmospheric heat transport

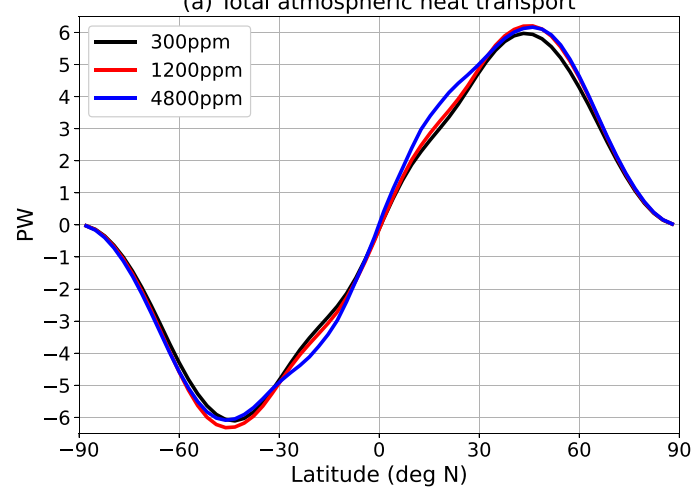

(b) Dry and moist atmospheric heat transport

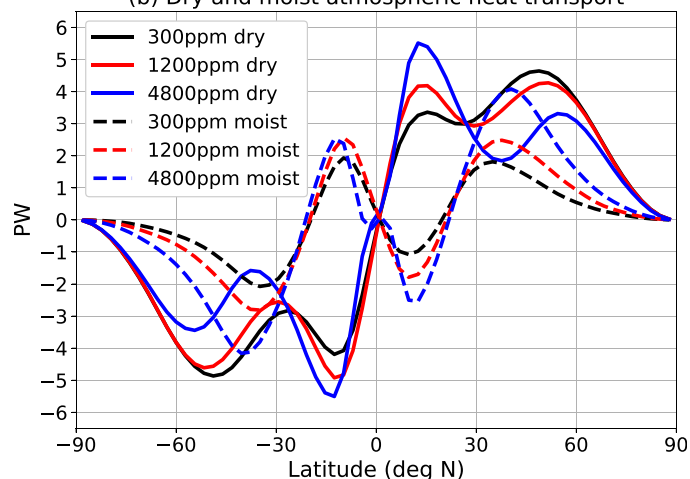

FIG. 2. Atmospheric heat transport. (a) Total and (b) dry and moist northward atmospheric heat transport for the 300 ppm (black), 1200 ppm (red), and 4800 ppm (blue) simulations.

Socioeconomic Pathway 5-8.5 (SSP5-8.5)]. Figures 6a and 6c show the monthly Northern Hemisphere sea ice area; Figs. $6 \mathrm{~b}$ and $6 \mathrm{~d}$ show the Arctic land (solid) and ocean (dashed) surface temperature change between 2270-2300 and 2150-2180. For both models, once the sea ice is melted the Arctic land warms more in winter and less in summer than does the Arctic Ocean, which warms uniformly throughout the year. We note that the two averaging periods (2270-2300 and 2150-2180) do not correspond to a climate in equilibrium, unlike the idealized model simulations. Differences in cloud feedbacks, ocean circulation, snow albedo feedback over land, and other processes may explain why the two models differ quantitatively. There (a) Annual-mean surface temperature

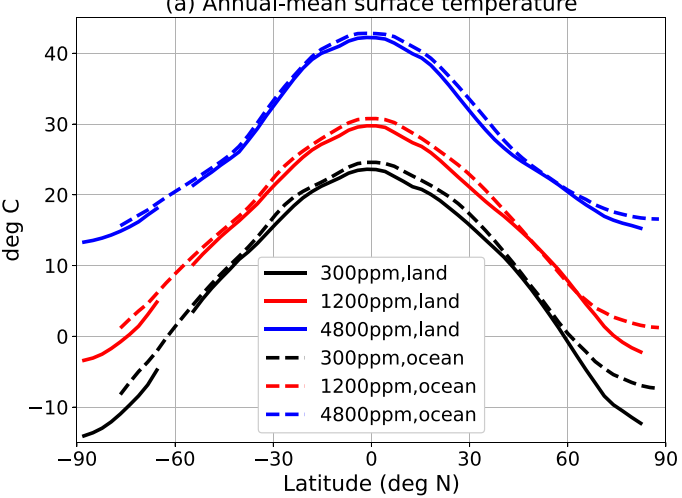

(c) Surface temperature (latitude $>70$ )

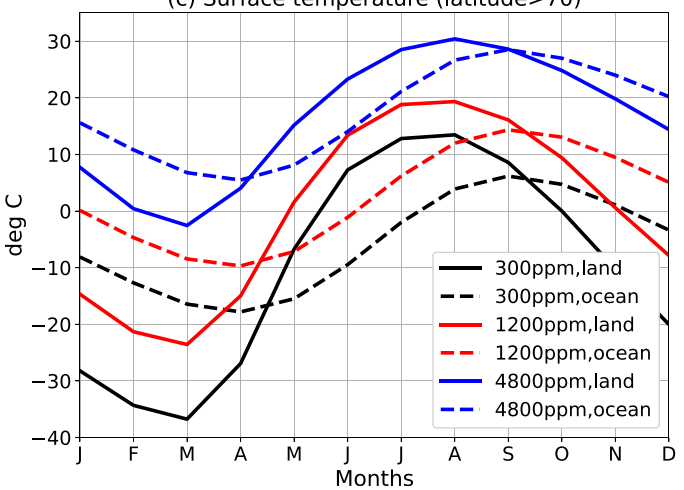

(b) Annual-mean surface temperature difference

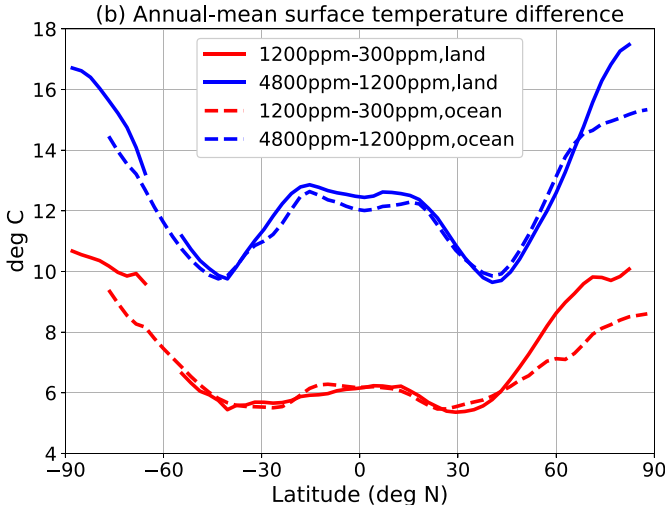

(d) Surface temperature difference (latitude $>70$ )

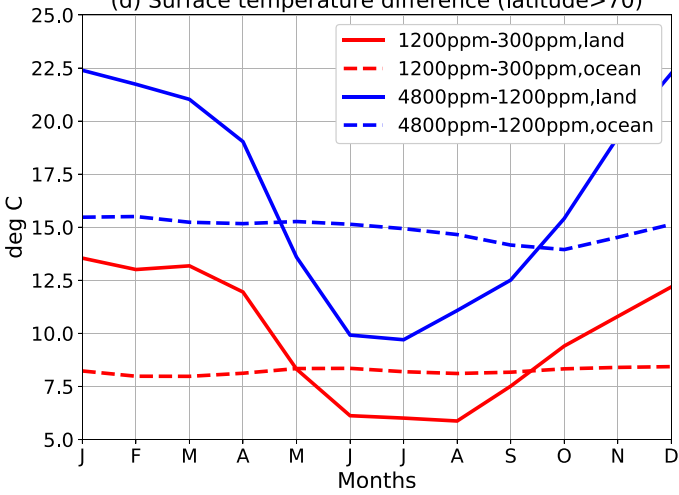

FIG. 3. (a) Surface temperature over land (solid) and ocean (dashed) for the $300 \mathrm{ppm}$ (black), $1200 \mathrm{ppm}$ (red), and $4800 \mathrm{ppm}$ (blue) simulations. (b) Surface temperature change over land and ocean between the 300 and $1200 \mathrm{ppm}$ simulations (red) and between the 1200 and $4800 \mathrm{ppm}$ simulations (blue). (c) Seasonality of surface temperature north of $70^{\circ} \mathrm{N}$ for land (solid) and ocean (dashed) for the $300 \mathrm{ppm}$ (black), $1200 \mathrm{ppm}$ (red), and $4800 \mathrm{ppm}$ (blue) experiments. (d) Surface temperature change north of $70^{\circ} \mathrm{N}$ for land (solid) and ocean (dashed) between the 300 and $1200 \mathrm{ppm}$ simulations (red) and between the 1200 and $4800 \mathrm{ppm}$ simulations (blue). 


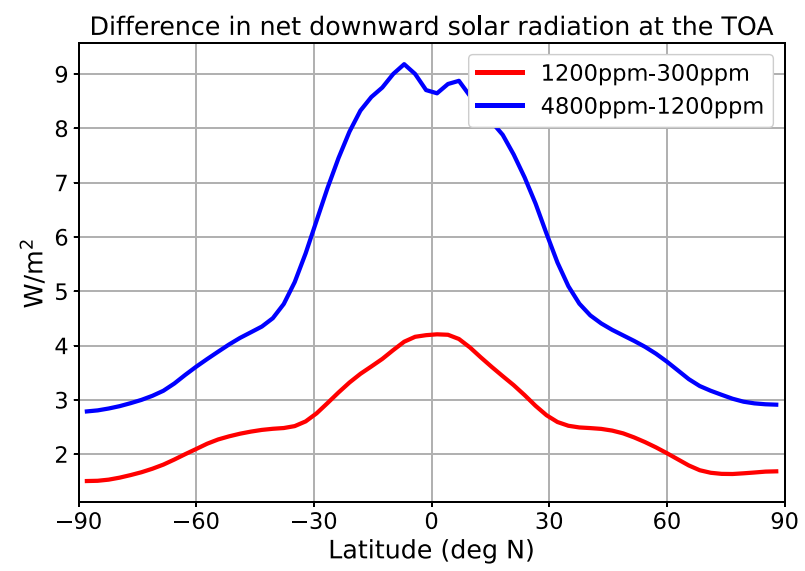

FIG. 4. Difference in net downward solar radiation at the top of the atmosphere between the 300 and 1200 ppm simulations (red) and between the 1200 and $4800 \mathrm{ppm}$ simulations (blue).

are also large differences in the response of permafrost to high-latitude warming, which impact surface heat fluxes, evaporation, and the snow-albedo feedback (Koven et al. 2013). However, their results are generally consistent with each other and with the results of our more idealized model. This prompts us to seek a simpler, robust explanation of the seasonality of high-latitude warming.
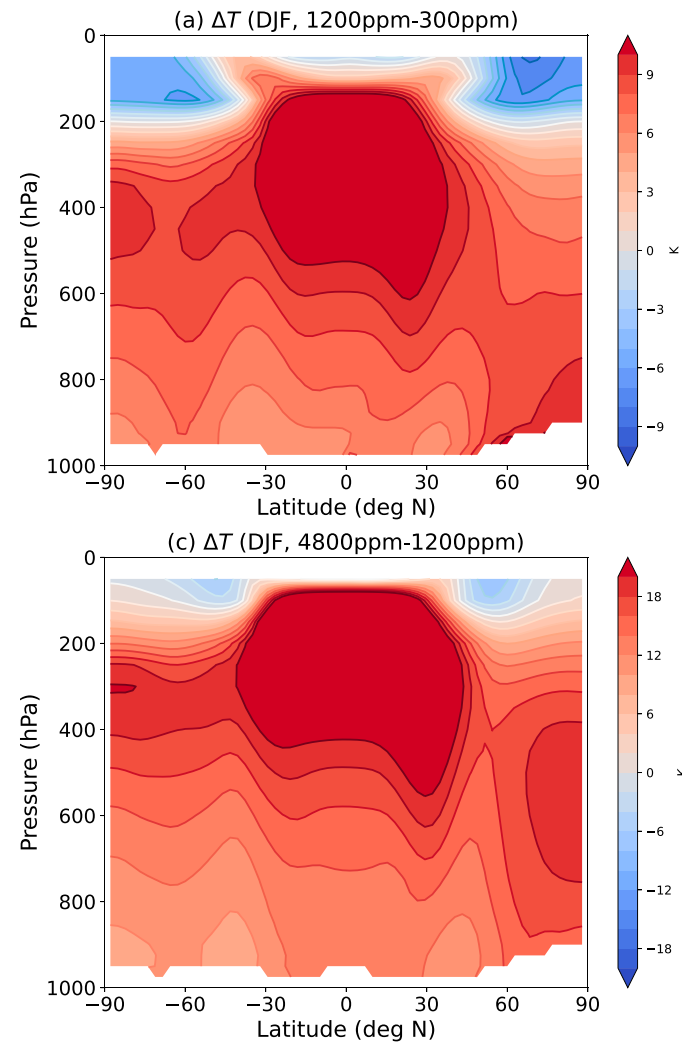

\section{Seasonality of surface temperature change}

We use a simple surface energy balance model to better understand the seasonality of high-latitude surface temperature. The surface energy balance in the model is given by

$$
C \frac{d T_{S}}{d t}=\mathrm{SW}_{\text {net }}+\mathrm{LW}_{\text {down }}-\sigma T_{S}^{4}+\mathrm{SH}+\mathrm{LH},
$$

where $C$ is the surface heat capacity (equal to $8.3 \times$ $10^{7} \mathrm{~J} \mathrm{~m}^{-2} \mathrm{~K}^{-1}$ for the ocean surface and $8.3 \times 10^{6} \mathrm{~J} \mathrm{~m}^{-2} \mathrm{~K}^{-1}$ for the land surface), $T_{S}$ is the surface temperature, $t$ is time, $\mathrm{SW}_{\text {net }}$ is the net downwelling shortwave radiative flux at the surface, $\mathrm{LW}_{\text {down }}$ is the downwelling longwave radiative flux at the surface, $\sigma$ is the Stefan-Boltzmann constant (so that $\sigma T_{S}^{4}$ is the upwelling longwave radiative flux emitted from the surface), and $\mathrm{SH}$ is the sensible heat flux and $\mathrm{LH}$ the latent heat flux from the atmosphere to the surface. The quantities $T_{S}, \mathrm{SW}_{\text {net }}$, $\mathrm{LW}_{\text {down }}, \mathrm{SH}$, and $\mathrm{LH}$ are functions of time but not space. We use values from the GCM integrations for $C, \mathrm{SW}_{\text {net }}, \mathrm{LW}_{\text {down }}$, $\mathrm{SH}$, and $\mathrm{LH}$, averaged poleward of $70^{\circ} \mathrm{N}$, such that the only free variable is $T_{S}$, and for any given parameter set we integrate over 10 years, or until the model is in a seasonally varying steady state.

Figure 7 shows the input to the surface energy balance model, focusing on the difference between the 300 and $1200 \mathrm{ppm}$ simulations. Figure $7 \mathrm{a}$ shows the net shortwave
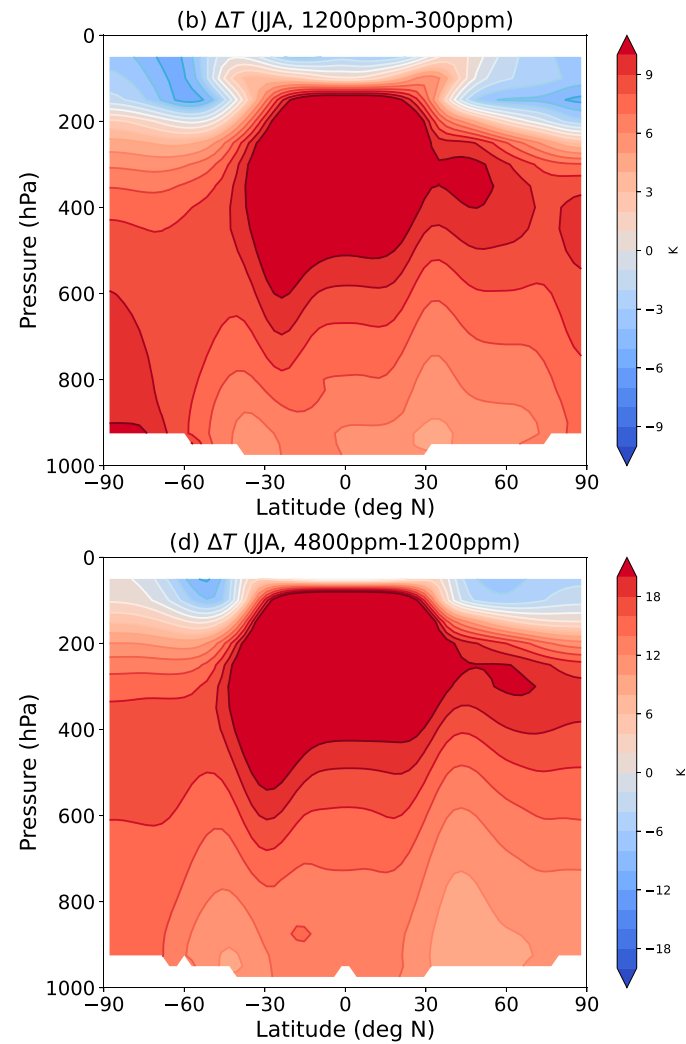

FIG. 5. Atmospheric temperature change (a),(b) between the 300 and $1200 \mathrm{ppm}$ simulations and (c),(d) between the 1200 and $4800 \mathrm{ppm}$ simulations for Northern Hemisphere (left) winter and (right) summer. 

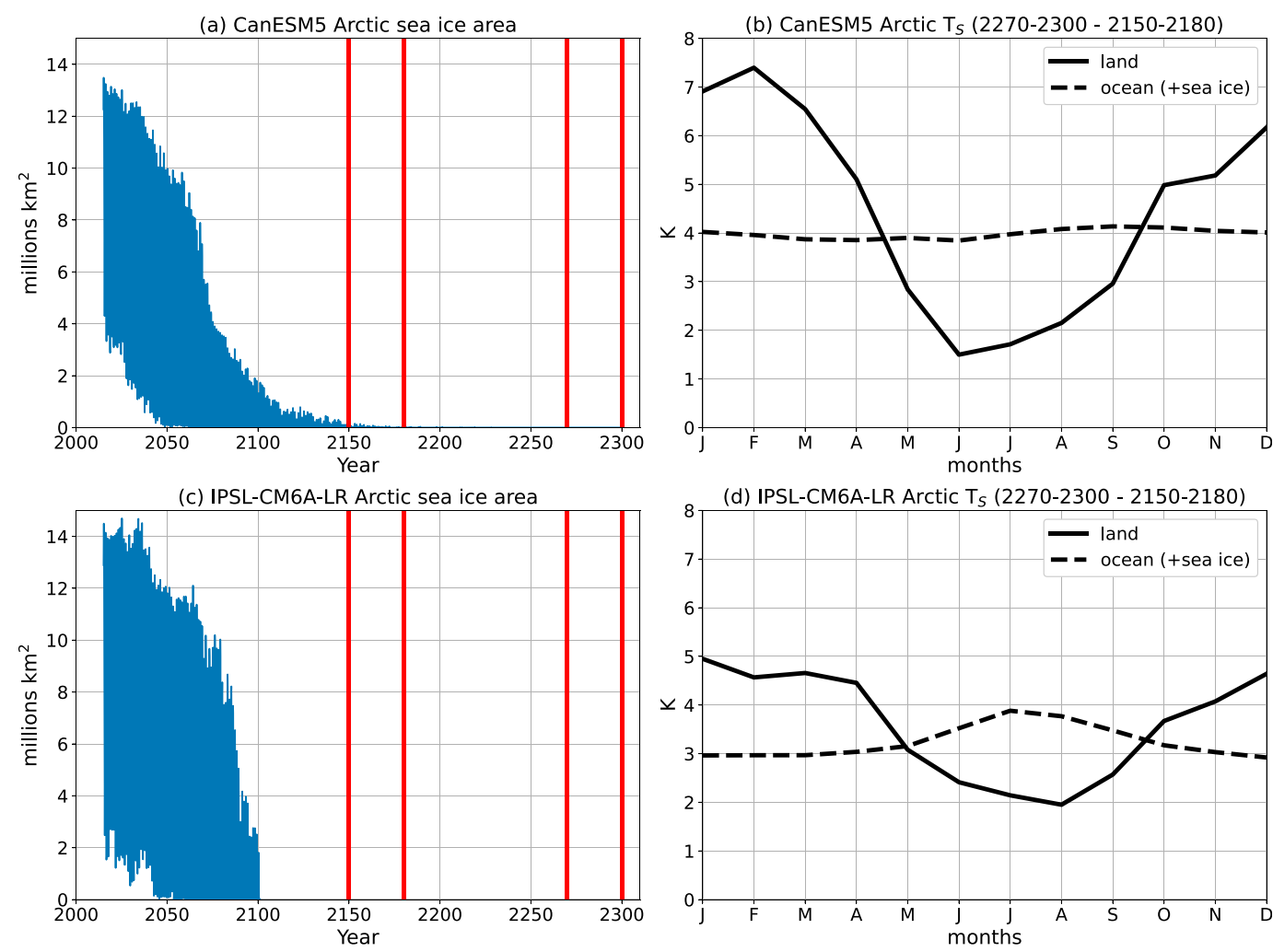

FIG. 6. Seasonality of Arctic land and ocean surface temperature change in two comprehensive climate models in a high emissions scenario when Northern Hemisphere sea ice almost vanishes. (a),(c) Monthly Arctic sea ice area (blue shading) with the averaging limits in red (2150, 2180, 2270, 2300). (b),(d) Arctic land (solid) and ocean (dashed) surface temperature change between 2270-2300 and 2150-2180. The emissions scenario is the Shared Socioeconomic Pathway 5-8.5 (SSP5-8.5). The two models used are CanESM5 in (a) and (b) and IPSL-CM6A-LR in (c) and (d). Those were the only models available that extended to 2300 in the SSP5-8.5 scenario. Arctic surface temperatures are averaged poleward of $70^{\circ} \mathrm{N}$. Note that the data for sea ice area for IPSL-CM6A-LR stop at year 2100 .

radiation at the surface for the $300 \mathrm{ppm}$ (black) and $1200 \mathrm{ppm}$ (blue) simulations. The increased atmospheric absorption of solar radiation at $1200 \mathrm{ppm}$ leads to a small decrease in shortwave flux at the surface. Figure $7 \mathrm{~b}$ shows the downwelling longwave radiation at the surface for land (solid) and ocean (dashed). The increase in downwelling longwave is approximately the same over ocean and land and has a seasonal cycle, which could also contribute to the seasonality in surface warming.

Figure 7c shows the seasonal cycle of evaporative cooling over land and ocean. While it is small year-round over ocean and in winter over land, it is comparable to downwelling longwave radiation in summer over land. Moreover, there is an increase in evaporative cooling over land during the summer and over ocean during the winter. This pattern is caused by the nonlinear temperature dependence of saturation vapor pressure as the surface evaporation flux is proportional to the difference in saturation specific humidity calculated using the surface and lowest model temperatures [Eq. (10) in Vallis et al. (2018)]. In winter (summer), the ocean (land) surface is warmer than the overlying air. Hence an increase in temperature will lead to a higher increase in the saturation vapor pressure calculated from the surface temperature, which leads to an increase in evaporative flux.

Figure 8a shows results from the surface energy balance model, comparing the seasonality of surface temperature change over land and ocean with results from the GCM data for the difference between the 300 and $1200 \mathrm{ppm}$ simulations. The simple model fits the GCM data quite well, which is expected since all the terms of Eq. (1) except the surface temperature evolution itself are taken from the GCM. We can now use the simple model to explore the main drivers of the difference in surface temperature change between high-latitude ocean and land.

To isolate the role of the increase in evaporative heat flux in the seasonality in warming, we remove the sensible heat flux, the seasonality of the change in downwelling longwave radiation at the surface [the change in downwelling longwave radiation is replaced by its average change over time $\left(45 \mathrm{~W} \mathrm{~m}^{-2}\right)$ ], and the nonlinearity of the temperature dependence of surface longwave emission from Eq. (1) - note that $\sigma T^{4}$ is replaced with $\left[250+4 \times\left(T_{s}-250\right)\right]$. We integrate the following modified version of Eq. (1): $C\left(d T_{S} / d t\right)=\mathrm{SW}_{\text {net }}+\mathrm{LW}_{\text {down }}-$ $\left[250+4 \times\left(T_{S}-250\right)\right]+$ LH. Figure $8 \mathrm{~b}$ compares the surface 


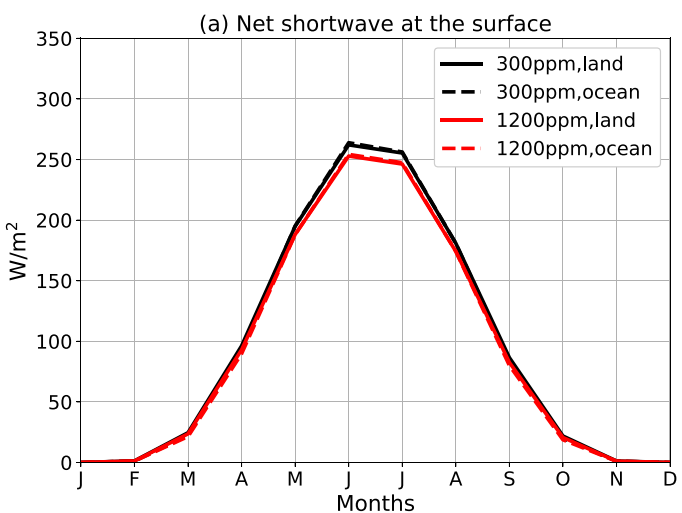

(c) Latent heat flux (positive upwards)

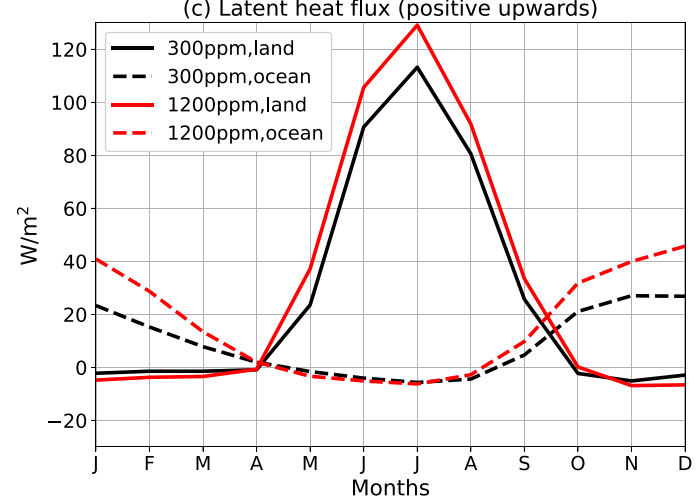

(b) Longwave down at the surface

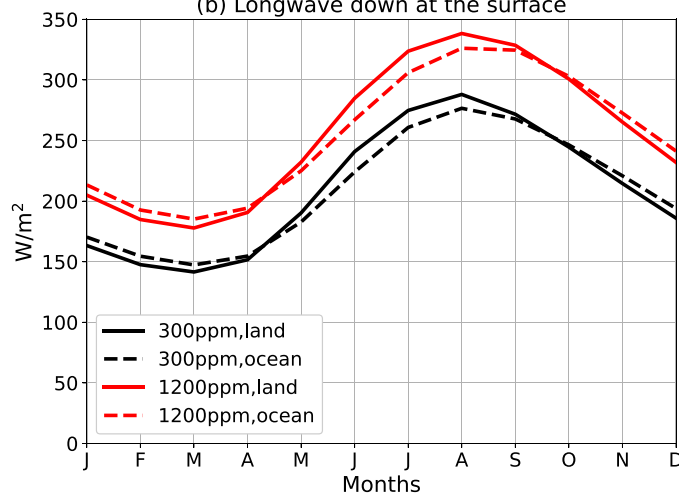

(d) Sensible heat flux (positive upwards)

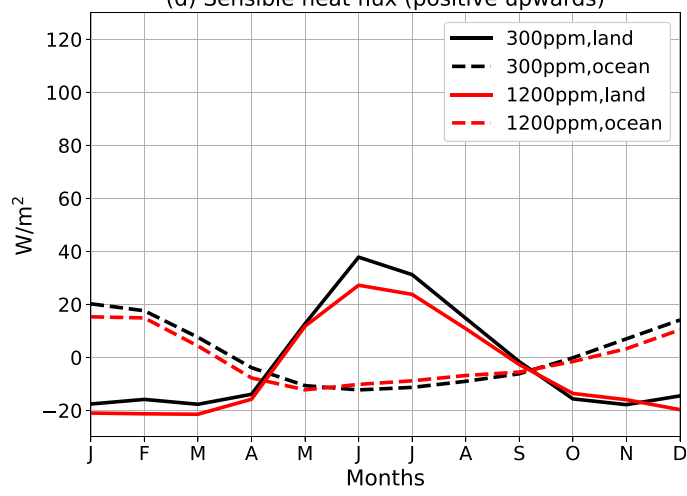

FIG. 7. Inputs to the surface energy balance model prescribed from the GCM. Values for the $300 \mathrm{ppm}$ (black) and $1200 \mathrm{ppm}$ (red) over land (solid) and ocean (dashed) are averaged poleward of $70^{\circ} \mathrm{N}$. (a) Net shortwave radiation at the surface (positive downward). (b) Downward longwave radiation at the surface (positive downward). (c) Evaporative cooling at the surface (positive upward). (d) Sensible heat flux at the surface (positive upward).

energy balance model with the GCM data in the same way as Fig. 8a. In isolation, the increase in evaporative heat flux causes a slight summer amplification of ocean warming and a winter amplification of the land warming, which is smaller than the total winter amplification from the GCM. However, the land surface evaporates as if it was ocean in this setup. Hence, in two additional simulations, we test the importance of land surface evaporation by reducing it by a factor of 10 [specifically, $\beta$ in Eq. (10) in Vallis et al. (2018) is set to 0.1], and perform the same analysis (dash-dotted line in Fig. 8b). The
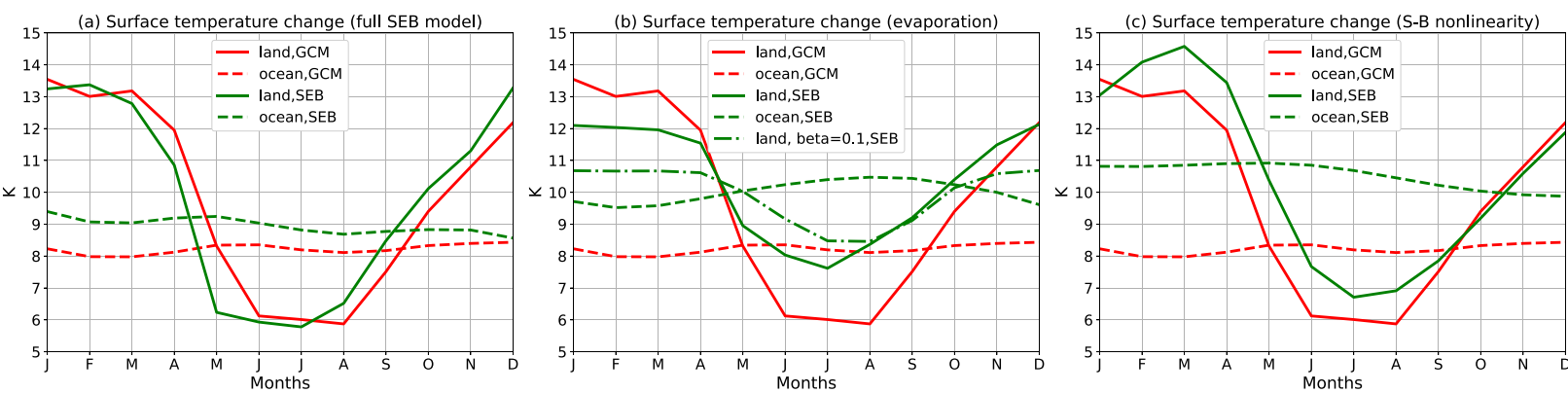

FIG. 8. Surface energy balance model results for the difference between the 300 and $1200 \mathrm{ppm}$ simulations. (a) The full surface energy balance model (green) accurately reproduces the GCM data (red). (b) The simple surface energy balance model (green) with no sensible heat flux, a linearized temperature dependence of surface longwave emission, and no seasonality in the change in downwelling longwave radiation at the surface has a winter amplified land surface temperature change (green, solid) and no seasonality in ocean surface temperature change (green, dashed). When land surface evaporative resistance [ $\beta$ in Eq. (10) in Vallis et al. (2018)] is set to 0.1, the winter amplification of land surface temperature change is reduced (green, dash-dotted). (c) The simple surface energy balance model (green), with no surface fluxes and no seasonality in the change in downwelling longwave radiation at the surface, reproduces the patterns of land (solid) and ocean (dashed) surface temperature change. 
increase in evaporative heat flux is smaller and leads to less winter amplification of land surface warming.

We now remove the surface fluxes ( $\mathrm{SH}$ and $\mathrm{LH}$ ) and the seasonality of the change in downwelling longwave radiation at the surface from Eq. (1). Figure 8c compares the surface energy balance model with the GCM data in the same way as Fig. 8 a. Without the evaporative cooling over land in summer, the surface temperature in the simple surface energy balance model gets significantly warmer over land in summer for both the 300 and $1200 \mathrm{ppm}$ simulations (not shown), but this does not affect the surface temperature change. The increase in evaporative cooling over ocean in winter leads this simple model to overestimate the warming year-round as seasonal differences in fluxes are smoothed out in time by the ocean's large surface heat capacity. The changes in evaporative cooling and downwelling longwave radiation seemed like good candidate explanations for the difference in seasonality of warming over land and ocean. However, the land surface temperature in the simple surface energy balance model still has a large seasonality compared to that of the ocean.

The two aspects of the simple surface energy balance model that yield the difference in seasonality in surface temperature change between land and ocean are the surface heat capacity $C$ and the nonlinearity of the temperature dependence of the surface longwave emission $\sigma T_{S}^{4}$. A smaller heat capacity implies that less energy is required to change the temperature of the surface, hence the climatological seasonality of land is larger and any energy perturbation to the surface has a more immediate impact on surface temperature. Furthermore, the nonlinearity of $\sigma T_{S}^{4}$ means that, for a smaller starting temperature, a larger increase in temperature is required to reach a given increase in longwave emission and balance the new forcing.

The higher climatological seasonality of land surface temperatures means that the land's temperature response will also have a large seasonality: the temperature response will be larger when the starting temperature is low (in winter) and smaller when the starting temperature is high (in summer). The ocean's large surface heat capacity means the climatological seasonality is smaller ( $25 \mathrm{vs} 50 \mathrm{~K}$ for land), and that any energy perturbation's impact on surface temperature will be smoothed out and affect the annual mean temperature change, rather than a given month.

The above results can be straightforwardly interpreted as a damped forced oscillator obeying the equation

$$
C \frac{d T_{S}}{d t}=-\sigma T_{S}^{4}+A \cos \omega t+D
$$

where $A$ is the amplitude of the seasonal forcing and $D$ is a constant representing the time-invariant components of the forcing. This is similar to Eq. (1) in Dwyer et al. (2012). If the seasonal cycle is not too large, we can linearize temperature around some mean temperature $\overline{T_{S}}$ to give

$$
C \frac{d T_{S}^{\prime}}{d t}=-M T_{S}^{\prime}+A \cos \omega t
$$

where $M=4 \sigma{\overline{T_{S}}}^{3}$ and $T_{S}^{\prime}=T_{S}-\overline{T_{S}}-D / M$, and we henceforth drop the prime on $T_{S}$. The solution of (3), after transients have died, is $T_{S}=T_{0} \cos (\omega t+\phi)$ where
TABLE 1. Amplitude of seasonal oscillation $\left(T_{0}\right)$ for ocean and land surfaces and for $\bar{T}=260 \mathrm{~K}$ and $\bar{T}=280 \mathrm{~K}$.

\begin{tabular}{lcccc}
\hline \hline & $\begin{array}{c}\text { Ocean, } \\
260 \mathrm{~K}\end{array}$ & $\begin{array}{c}\text { Land, } \\
280 \mathrm{~K}\end{array}$ & $\begin{array}{c}\text { Ocean, } \\
280 \mathrm{~K}\end{array}$ & $\begin{array}{c}\text { Land, } \\
260 \mathrm{~K}\end{array}$ \\
\hline$C\left(10^{6} \mathrm{~J} \mathrm{~m}^{-2} \mathrm{~K}^{-1}\right)$ & 83 & 8.3 & 83 & 8.3 \\
$M\left(\mathrm{~W} \mathrm{~m} \mathrm{~K}^{-1}\right)$ & 4.98 & 4.98 & 3.99 & 3.99 \\
$T_{0}(\mathrm{~K})$ & 14.7 & 58.1 & 14.5 & 48.1 \\
\hline
\end{tabular}

$$
T_{0}=\frac{A}{\left(C^{2} \omega^{2}+M^{2}\right)^{1 / 2}} \quad \text { and } \quad \phi=\arctan \left(\frac{C \omega}{M}\right) .
$$

The amplitude of the seasonal oscillation (i.e., $T_{0}$ ) naturally diminishes for larger $C$, so that the seasonal cycle over land is larger than that over the ocean. Less obviously, the amplitude diminishes as $M$ increases, and since $M$ is a function of temperature, a warmer climate will have a smaller seasonal cycle [at least to the extent that the seasonal cycle is described by (1) and (2)].

Putting in a few numbers, for $2 \mathrm{~m}$ of water at $270 \mathrm{~K}$ we find that $C \omega \approx 1.6 \mathrm{~W}\left(\mathrm{~m}^{2} \mathrm{~K}\right)^{-1}$ and $M=4.5 \mathrm{~W}\left(\mathrm{~m}^{2} \mathrm{~K}\right)^{-1}$, so the heat capacity and temperature effects are evidently comparable and changes in both may be important. Table 1 shows values of the amplitude of the seasonal oscillation for the high-latitude land and ocean for $\overline{T_{S}}=260 \mathrm{~K}$ and $\overline{T_{S}}=280 \mathrm{~K}$. The amplitude of the seasonal oscillation $T_{0}$ is almost the same for the two values for the ocean, whereas it is reduced by $10 \mathrm{~K}$ for land, generally consistent with our simulation results (Fig. 3).

\section{Seasonality of atmospheric temperature change}

Changes in downwelling longwave radiation at the surface are coupled to the surface temperature change and they should not be considered as independent variables. Nevertheless, in these simulations, the downwelling longwave radiation at the surface does not differ much between land and ocean while the surface temperatures do (Figs. $3 c$ and $7 b$ ). This can also be seen in the atmospheric temperatures over land and ocean: Fig. 9a shows the atmospheric and surface temperature averaged poleward of $70^{\circ} \mathrm{N}$ over ocean (dashed, cross) and land (solid, dot) for the winter (blue) and summer (red) months. Figure $9 \mathrm{~b}$ shows the atmospheric and surface temperature change between the 300 and 1200 ppm simulations. While the ocean's climatological surface temperature and surface temperature change have a small seasonality compared to land, the atmospheric temperature and atmospheric temperature change are the same for land and ocean. This suggests that while surface temperatures over land and ocean can remain relatively uncoupled, atmospheric temperatures tend to homogenize.

Figure 10 shows the convective, advective, and radiative temperature tendencies over land and ocean for the $300 \mathrm{ppm}$ simulation poleward of $70^{\circ} \mathrm{N}$, for Northern Hemisphere winter and summer. In winter, advection warms the atmosphere near the land surface and cools the atmosphere near the ocean surface, and vice versa in summer. That is, advection acts to homogenize the near-surface atmospheric temperatures over 
(a) Temperature (300ppm, lat>70)

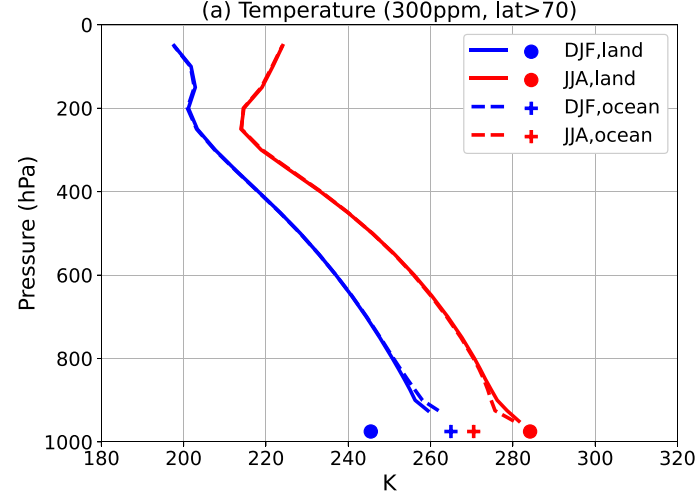

(b) $\Delta T(1200 \mathrm{ppm}-300 \mathrm{ppm}$, lat $>70)$

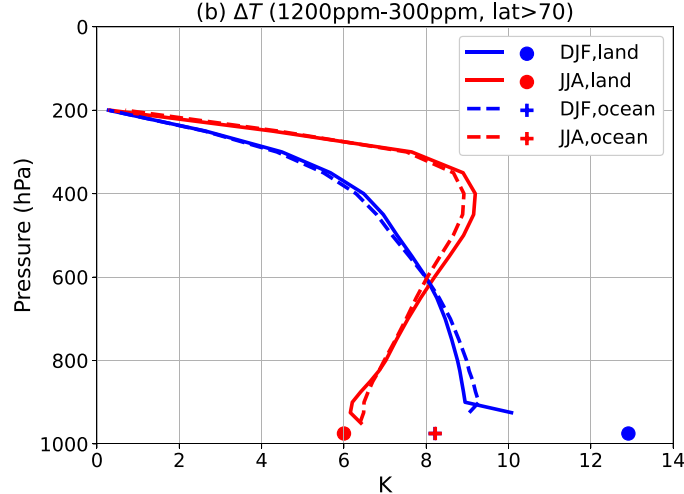

FIG. 9. (a) Atmospheric and surface temperature over ocean (dashed, cross) and land (solid, dot) for winter (blue) and summer (red) poleward of $70^{\circ}$ N. (b) Atmospheric and surface temperature change between the 300 and $1200 \mathrm{ppm}$ simulations. Note that the DJF and JJA ocean surface temperature changepoints are coincidental in (b).

land and ocean. We also see that the main equilibrium is between radiation and advection, except over land during summer when convection is triggered and the main equilibrium is between radiation and convection. This explains the surfaceenhanced warming in winter and more vertically homogeneous warming in summer (Fig. 5). Finally, there is convection over ocean in winter, which may be due to the ocean surface being warmer than the atmosphere in winter because of its high heat capacity.

To clarify the relationship between the atmospheric energy balance and vertical temperature change structure, we run so-called all-land and all-ocean simulations where the aquaplanet's mixed layer depth is uniformly 2 and $20 \mathrm{~m}$, respectively, at 300 and 1200 ppm. Figure 11 is analogous to Fig. 9 but for the all-ocean and all-land experiments. The higher surface heat capacity in the all-ocean experiments results in a very small seasonal cycle in surface and atmospheric temperature, and temperature change. Inversely, the seasonal cycle is very large for the all-land experiment (approximately $55 \mathrm{~K}$ for the surface temperature), and the surface temperature change is higher in winter $(13.5 \mathrm{~K})$ and lower in summer $(5.8 \mathrm{~K})$. The vertical structure of atmospheric temperature change is more or less homogeneous in the all-ocean experiment. However, in the all-land experiment, warming is bottom heavy in winter and top heavy in summer. Figure 12 is analogous to Fig. 10 but for the all-ocean and the all-land experiments. In the all-land experiments, there is a clear seasonality between radiativeconvective equilibrium in summer and radiative-advective equilibrium in winter. In the all-ocean experiments, the atmosphere is close to radiative-advective equilibrium yearround, with slightly more advection in winter.

These two additional simulations show that the atmospheric temperature change in the initial simulations is a mix of these two extremes ("all-land" and "all-ocean"), with advection smoothing out the differences in atmospheric temperature driven by the differing surface temperatures of ocean and land. The vertical structure of high-latitude temperature change is driven by what happens at the surface: if it gets warm enough at the surface, deep convection is triggered, which causes vertical mixing and a more vertically homogeneous atmospheric warming. In the absence of convection, the main balance is between advective warming and radiative cooling and
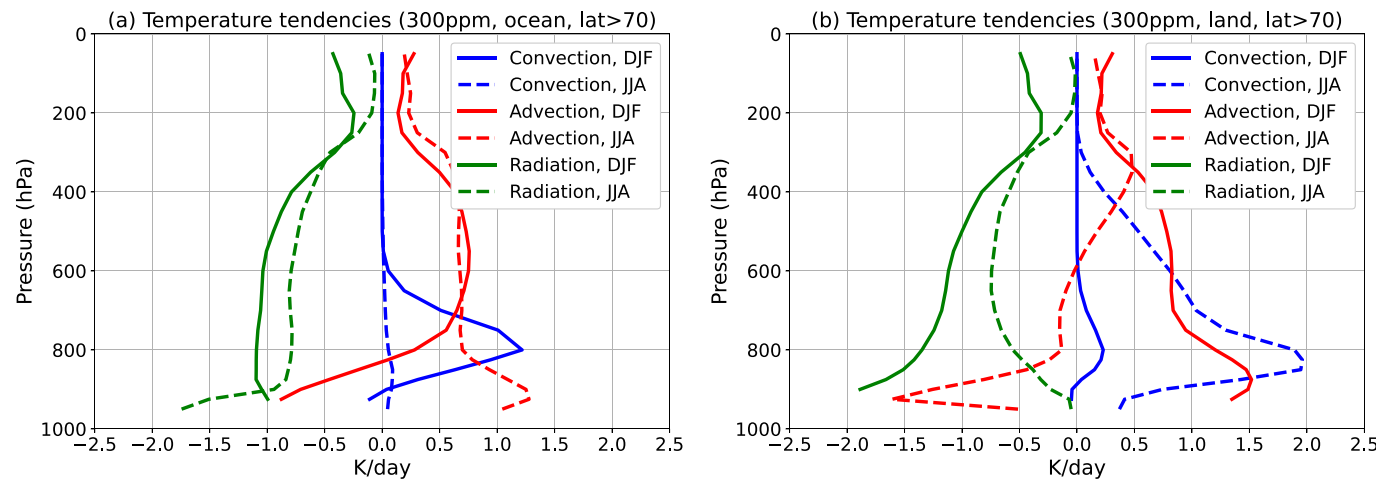

FIG. 10. Atmospheric temperature tendency budget for the $300 \mathrm{ppm}$ simulation over (a) ocean and (b) land for latitudes poleward of $70^{\circ} \mathrm{N}$. It shows the convective (blue), advective (red), and radiative (green) temperature tendencies for Northern Hemisphere winter (solid) and summer (dashed). 
(a) Temperature (300ppm, lat>70)

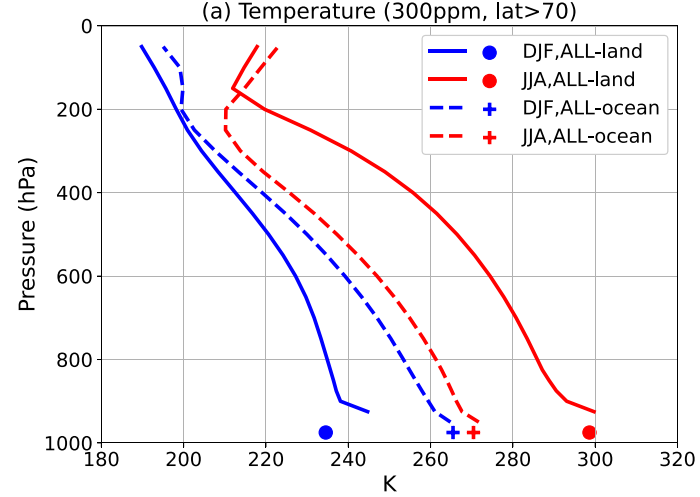

(b) $\Delta T$ (1200ppm-300ppm, lat $>70)$

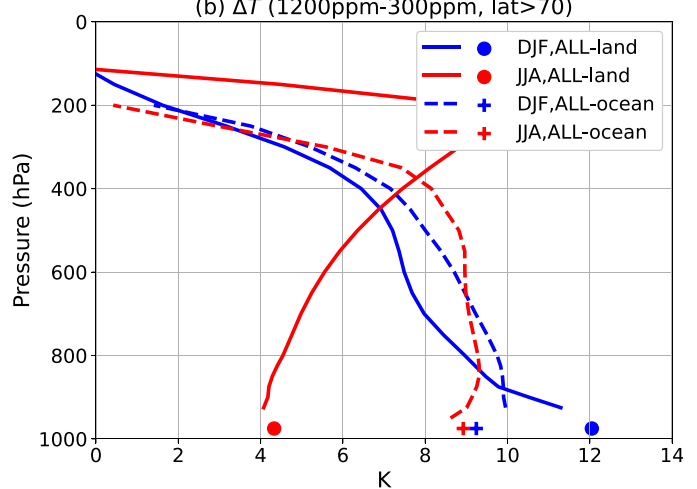

FIG. 11. As in Fig. 9, but for the all-ocean and all-land simulations, which are two separate sets of simulations where the mixed layer depth is set uniformly to 20 and $2 \mathrm{~m}$, respectively.

atmospheric warming is enhanced near the surface (Cronin and Jansen 2016; Henry et al. 2021). Since the high-latitude land gets warm enough in summer to trigger deep convection, the warming is more vertically homogeneous. For the difference between the 1200 and $4800 \mathrm{ppm}$ simulations, there is deep convection triggered year-round at high latitudes, and hence the atmospheric warming is never enhanced near the surface (Fig. 5).

\section{Discussion and conclusions}

Various lines of evidence suggest that, as greenhouse gases increase, the Arctic land warms more in winter and less in summer, thus reducing the seasonality over land in warm climates. In this paper we have identified a robust mechanism for this that applies both to the warm climates of the past and to the expected warming of the future. The reduced seasonality may contribute to the reason that some of the warm climates of the past were able to sustain above freezing yearround temperatures, even in continental winters at high latitudes and without excessively warm tropical temperatures. The early Eocene, for example, had a reduced latitudinal surface temperature gradient and its Arctic continents had especially warm winters compared to those of today.
Similarly, current warming trends and projections of future warming show a polar amplified surface temperature change and more Arctic warming in winter.

Experiments with an idealized GCM show that the surface temperature change from increasing $\mathrm{CO}_{2}$ is polar amplified, even in the absence of sea ice effects. This is, however, only a near-surface phenomenon-the meridional temperature gradient in midatmosphere and the total meridional atmospheric heat transport are virtually unchanged: the increase in energy transport by moist processes (because the atmosphere is warmer and wetter) is closely compensated by a decrease in dry atmospheric heat transport. The increase in Arctic land surface temperature is twice as large in winter as in summer. Also, the seasonality of the vertical structure of Arctic warming is consistent with recent warming trends: surface enhanced in winter and more vertically homogeneous in summer. Similar results are found in two comprehensive climate models under a high emissions scenario; specifically, even after all sea ice is melted, Arctic land continues to warm more in winter than summer by at least a factor of 2 , whereas the ocean continues to warm uniformly throughout the year.

The seasonality of high-latitude land warming can be explained with a simple surface energy balance model. The combination of the small surface heat capacity of land (which
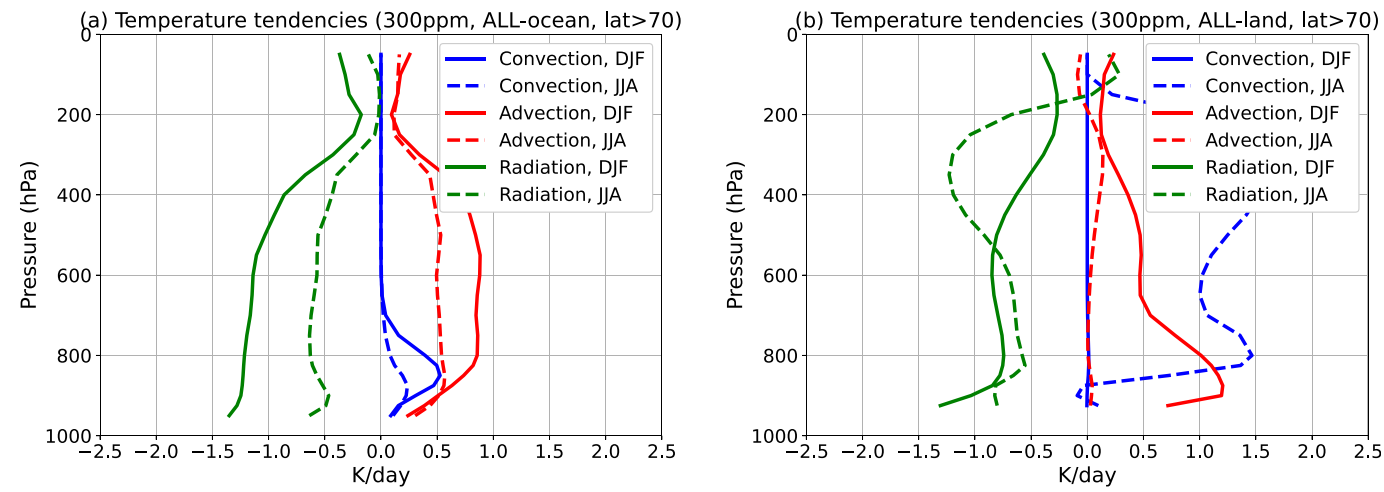

FIG. 12. As in Fig. 10, but for the all-ocean and all-land simulations, which are two separate sets of simulations where the mixed layer depth is set uniformly to 20 and $2 \mathrm{~m}$, respectively. 
leads to a large climatological seasonality in temperature over land) and the nonlinearity of the temperature dependence of surface longwave emission (which leads to cold temperatures warming more as $\mathrm{CO}_{2}$ increases) is largely responsible for the reduction in seasonality over land as $\mathrm{CO}_{2}$ levels increase. The downward infrared radiation, which is one of the primary forcings of surface temperature, is actually fairly similar over land and ocean because advection smooths out differences in near-surface atmospheric temperature over land and ocean. The increase in evaporation over land also leads to winter amplification of warming over land, although restricting evaporation over land reduces this contribution.

An understanding of the atmospheric warming then follows by connecting the changes in the surface energy balance to the mechanisms determining the vertical structure temperature. The vertical structure of high-latitude warming differs considerably from that in tropics. In the latter the warming is top heavy because the atmosphere is near radiative-convective equilibrium and the atmospheric temperature profile more or less follows a moist adiabat. In contrast, in much of the high latitudes (especially in winter) the atmosphere is near radiative-advective equilibrium and this promotes surface-enhanced atmospheric warming (Payne et al. 2015; Henry et al. 2021). In the first quadrupling of $\mathrm{CO}_{2}$, convection is only triggered over land in summer, which leads to surface-enhanced warming in winter and more vertically homogeneous warming in summer. Consistently, in all-ocean simulations the Arctic atmosphere is in radiativeadvective equilibrium year-round and the warming is surface enhanced. In all-land simulations, there is a clear seasonality between radiative-convective summer, with top-heavy warming, and radiative-advective winter with surfaceenhanced warming.

The mechanisms we have identified apply to both warm past climates and potentially warm future climates. The main differences between the two, in reality, are the continental configuration, the vegetation, and the presence of sea and land ice and these will, of course, have quantitative effects. We have also neglected the presence of clouds, and the fact that convection does occur over high-latitude land in winter suggests that cloud feedbacks may be increasingly important in warm climates (e.g., Abbot and Tziperman 2008; Cronin and Tziperman 2015). Similarly, the continuing reduction of sea ice is likely to affect the seasonality of Arctic warming in climates of the near future. A quantitative picture of the seasonality at high latitudes, and how it may differ in warm climates, will require full consideration of the interaction of lapse rate changes, sea ice, surface heat storage, ocean circulation effects, clouds, and potentially other factors. The path toward that picture will require an understanding of the role of these various components in isolation as well as acting as a whole.

Acknowledgments. We wish to thank all the Isca team for many discussions about climate and modeling, and especially Stephen Thomson and Ruth Geen for help with the model setup and analysis. We also thank Eli Tziperman and Camille Hankel for a number of fruitful conversations about polar climates. This work was supported by the "Dynamics of Warm
Past and Future Climates" NERC Grant NE/T00942X/1 under a NERC-NSF partnership.

Data availability statement. The code to reproduce the figures is available at https:/github.com/matthewjhenry/ simple-seasonality-arctic and the data are available at https:// zenodo.org/record/4529135.

\section{REFERENCES}

Abbot, D. S., and E. Tziperman, 2008: Sea ice, high-latitude convection, and equable climates. Geophys. Res. Lett., 35, L03702, https://doi.org/10.1029/2007GL032286.

Armour, K. C., N. Siler, A. Donohoe, and G. H. Roe, 2019: Meridional atmospheric heat transport constrained by energetics and mediated by large-scale diffusion. J. Climate, 32, 3655-3680, https://doi.org/10.1175/JCLI-D-18-0563.1.

Beerling, D. J., and D. L. Royer, 2011: Convergent Cenozoic $\mathrm{CO}_{2}$ history. Nat. Geosci., 4, 418-420, https://doi.org/10.1038/ ngeo1186.

Bintanja, R., and E. van der Linden, 2013: The changing seasonal climate in the Arctic. Sci. Rep., 3, 1556, https://doi.org/10.1038/ srep01556.

Cronin, T. W., and E. Tziperman, 2015: Low clouds suppress Arctic air formation and amplify high-latitude continental winter warming. Proc. Natl. Acad. Sci. USA, 112, 11490-11495, https://doi.org/10.1073/pnas.1510937112.

— librium as a model for high-latitude climate. Geophys. Res. Lett., 43, 449-457, https://doi.org/10.1002/2015GL067172.

Dwyer, J. G., M. Biasutti, and A. H. Sobel, 2012: Projected changes in the seasonal cycle of surface temperature. J. Climate, $\mathbf{2 5}$, 6359-6374, https://doi.org/10.1175/JCLI-D-11-00741.1.

Eberle, J. J., H. C. Fricke, J. D. Humphrey, L. Hackett, M. G. Newbrey, and J. H. Hutchison, 2010: Seasonal variability in Arctic temperatures during early Eocene time. Earth Planet. Sci. Lett., 296, 481-486, https://doi.org/10.1016/ j.eps1.2010.06.005.

Evans, D., and Coauthors, 2018: Eocene greenhouse climate revealed by coupled clumped isotope- $\mathrm{Mg} / \mathrm{Ca}$ thermometry. Proc. Natl. Acad. Sci. USA, 115, 1174-1179, https://doi.org/ 10.1073/pnas.1714744115.

Frierson, D. M., 2007: The dynamics of idealized convection schemes and their effect on the zonally averaged tropical circulation. J. Atmos. Sci., 64, 1959-1976, https://doi.org/10.1175/ JAS3935.1.

Henry, M., T. M. Merlis, N. J. Lutsko, and B. E. Rose, 2021: Decomposing the drivers of polar amplification with a singlecolumn model. J. Climate, 34, 2355-2365, https://doi.org/ 10.1175/JCLI-D-20-0178.1.

Holland, M. M., and C. M. Bitz, 2003: Polar amplification of climate change in coupled models. Climate Dyn., 21, 221-232, https:// doi.org/10.1007/s00382-003-0332-6.

Huber, M., and R. Caballero, 2011: The early Eocene equable climate problem revisited. Climate Past, 7, 603-633, https:// doi.org/10.5194/cp-7-603-2011.

Hwang, Y.-T., and D. M. W. Frierson, 2010: Increasing atmospheric poleward energy transport with global warming. Geophys. Res. Lett., 37, L24807, https://doi.org/10.1029/ 2010 GL045440.

- —_, and J. E. Kay, 2011: Coupling between Arctic feedbacks and changes in poleward energy transport. Geophys. Res. Lett., 38, L17704, https://doi.org/10.1029/2011GL048546. 
Koven, C. D., W. J. Riley, and A. Stern, 2013: Analysis of permafrost thermal dynamics and response to climate change in the CMIP5 Earth system models. J. Climate, 26, 1877-1900, https://doi.org/10.1175/JCLI-D-12-00228.1.

Lu, J., and M. Cai, 2009: Seasonality of polar surface warming amplification in climate simulations. Geophys. Res. Lett., 36, L16704, https://doi.org/10.1029/2009GL040133.

Lunt, D. J., and Coauthors, 2012: A model-data comparison for a multi-model ensemble of early Eocene atmosphere-ocean simulations: EoMIP. Climate Past, 8, 1717-1736, https://doi.org/ 10.5194/cp-8-1717-2012.

Manners, J., J. M. Edwards, P. Hill, and J.-C. Thelen, 2017: SOCRATES: Suite Of Community RAdiative Transfer codes based on Edwards and Slingo. UK Met Office Tech. Rep., 87 pp., http://homepages.see.leeds.ac.uk/ lecsjed/winscpuse/ socrates_techguide.pdf.

McKim, B., N. Jeevanjee, and G. K. Vallis, 2021: Joint dependence of longwave feedback on surface temperature and relative humidity. Geophys. Res. Lett., submitted (preprint available at Earth and Space Science Open Archive, https://doi.org/ 10.1002/essoar.10506917.1).

Payne, A. E., M. F. Jansen, and T. W. Cronin, 2015: Conceptual model analysis of the influence of temperature feedbacks on polar amplification. Geophys. Res. Lett., 42, 9561-9570, https:// doi.org/10.1002/2015GL065889.

Pearson, P. N., B. E. van Dongen, C. J. Nicholas, R. D. Pancost, S. Schouten, J. M. Singano, and B. S. Wade, 2007: Stable warm tropical climate through the Eocene epoch. Geology, 35, 211214, https://doi.org/10.1130/G23175A.1.

Pithan, F., and T. Mauritsen, 2014: Arctic amplification dominated by temperature feedbacks in contemporary climate models. Nat. Geosci., 7, 181-184, https://doi.org/10.1038/ngeo2071.

Taylor, P. C., M. Cai, A. Hu, J. Meehl, W. Washington, and G. J. Zhang, 2013: A decomposition of feedback contributions to polar warming amplification. J. Climate, 26, 7023-7043, https:// doi.org/10.1175/JCLI-D-12-00696.1.

Thomson, S. I., and G. K. Vallis, 2019: The effects of gravity on the climate and circulation of a terrestrial planet. Quart. J. Roy. Meteor. Soc., 145, 2627-2640, https://doi.org/10.1002/qj.3582.

Vallis, G. K., and Coauthors, 2018: Isca, v1.0: A framework for the global modelling of the atmospheres of earth and other planets at varying levels of complexity. Geosci. Model Dev., 11, 843859, https://doi.org/10.5194/gmd-11-843-2018.

Winton, M., 2006: Amplified Arctic climate change: What does surface albedo feedback have to do with it? Geophys. Res. Lett., 33, L03701, https://doi.org/10.1029/2005GL025244. 